\title{
Comparison of Methicillin Resistant Staphylococcus aureus (MRSA) carriage among Health Care Workers serving in different areas of Cardiac Unit of a Tertiary Care Hospital, India
}

\author{
Rakhi Dixit* \\ 156, Sharanuganga, Vivekanand Nagar, Gokul Road, Hubli-580030, India \\ *Corresponding author
}

Keywords

Health care-

associated

infections,

Cefoxitin,

Nosocomial,

Antimicrobial

susceptibility

testing, Health care

worker, HA-MRSA

Article Info

Accepted:

10 June 2018

Available Online:

10 July 2018

\section{A B S T R A C T}

MRSA has become a leading cause of infections in both the community and in hospitals. Healthcare-associated MRSA (HA-MRSA) are the strains that circulate and are transmitted to individuals within health care facilities. The infected or colonized patients serve as the major reservoirs of MRSA in health care facilities. Transient carriage of MRSA on the hands of health care workers is the predominant mode of transmission from health care workers to patients and further from one patient to other patient. Our aim was to compare the prevalence of MRSA carriage among health care workers serving in different areas (Ward, ICU, Recovery and Emergency) of cardiac unit. This prospective study was conducted in the Department of Microbiology, Dayanand Medical College and Hospital, Ludhiana on 250 health care workers serving in different areas of cardiac unit. Screening was done by collecting swabs from hands and anterior nares. The specimens were processed by standard procedures for the isolation of $S$. aureus and methicillin

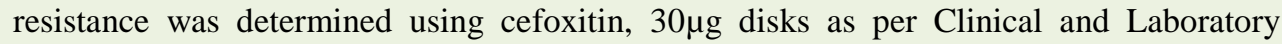
Standards Institute (CLSI) guidelines. Highest percentage of MRSA carriage was seen among the subjects working in recovery area (14\%). The prevalence of MRSA among the subjects working in emergency, wards and ICUs was found to be $12 \%, 8 \%$ and $5 \%$ respectively. The healthcare personnel require awareness regarding the nosocomial infections as well as bacterial colonization and should know their status of MRSA carriage and accordingly, take necessary measures to prevent possible transmission. Therefore, a continuous surveillance and improvement of hygiene standards in hospitals should be adopted.

\section{Introduction}

Health care-associated infections (HAIs) result in excess length of stay in hospitals, mortality and healthcare costs. In 2002, an estimated 1.7 million health care-associated infections occurred in the United States, resulting in 99,000 deaths (Klevens RM et al., 2007).. aureus strains which are resistant to the penicillinase-stable $\beta$ lactam antibiotics, like methicillin, cloxacillin and flucloxacillinare referred to as MRSA. MRSA strains are 
important because they have a remarkable ability to develop resistance to a variety of antimicrobials belonging to other classes like aminoglycosides, quinolones and macrolides. This poses a major threat to public health. Certain strains of MRSA are found to have the propensity to spread very quickly in hospitals (Sachdev et al., 2003).

Various studies have documented the occurrence of multiple drug resistant MRSA in hospitals and its subsequent transmission through the hands of health care workers (Barrett et al., 1968; Craven et al., 1981; Crossley et al., 1979). Methicillin resistance among $S$. aureus isolates was found to be 15$30 \%$ according to studies conducted in the 1990s (Edmond et al., 1999; Kesah et al., 2003; Tiemersma et al., 2004). However, recent studies done by Mekviwattanawong $\mathrm{S}$ et al., 2006 and Nimmo et al., 2007 have shown methicillin resistance among $S$. aureus isolates to be as high as $41.5 \%$.

MRSA has remained a major nosocomial pathogen in India as well. Percentage of MRSA among the $S$. aureus isolates varied from 20-80\% (Verma et al., 2000; Vidhani et al., 2001; Pulimood et al., 1996; Tahnkiwale et al., 2002) in the 1990s. Other studies conducted all over India from 2000-2009 have shown this percentage to vary from $30-55 \%$ (Rajaduraipandi et al., 2006; Anuprabha et al., 2003; Mulla et al., 2007; Chaudhury et al., 2007; Arora et al., 2010).

A number of studies have been conducted all over the world to know the prevalence of MRSA carriage in healthcare workers and the carriage rate was found to be $0.2 \%$ to $14 \%$ (Amorim et al., 2009; Shakya et al., 2010; Goyal et al., 2002; Kaminski et al., 2007; Vos et al., 2009; Askarian et al., 2009; Farzana et al., 2008; Ibarraa et al., 2008; Verwer et al., 2011; Vidhani et al., 2001). Screening for carriage of MRSA is fundamental to modern day nosocomial infection control, both for epidemiologic investigation and day-to-day decisions on barrier isolation (Safdar et al., 2003).

\section{Materials and Methods}

This prospective study was conducted in the Department of Microbiology, Dayanand Medical College and Hospital, Ludhiana on 250 health care workers of cardiac unit serving in different areas like wards, ICUs, recovery and emergency. The following data was collected from the health care workers screened: name, age, sex, designation and area of service. Using pre-moistened sterile cotton swabs, taking aseptic precautions, the specimens were collected from the anterior nares and hands of the health care workers. For collecting specimen from anterior nares, a pre-moistened sterile cotton swab was inserted into the nostril, to a depth of approximately $1 \mathrm{~cm}$, and rotated five times. For collecting specimen from hands, a pre-moistened sterile cotton swab was rubbed over the palm and web spaces.Swabs were transported to the laboratory in tubes containing sterile nutrient broth with $7 \% \mathrm{NaCl}$ (7\% salt broth). Tubes containing $7 \%$ salt broth with inoculated swab specimens were incubated overnight at $37^{\circ} \mathrm{C}$, subcultures were done from salt broth on blood agar plates which were again incubated overnight at $37^{\circ} \mathrm{C}$. S.aureuswas identified by standard techniques based on colony morphology, Gram's stain, catalase, slide and tube coagulase and mannitol fermentation test. Methicillin resistance was determined using cefoxitin, 30 $\mu \mathrm{g}$ disks using Modified KirbyBauer disk diffusion method on MuellerHinton agar. ATCC strain S. aureus 25923 was used as quality control. Isolates which showed cefoxitin $(30 \mu \mathrm{g})$ disk inhibition zone sizes of diameter less than or equal to $21 \mathrm{~mm}$ were considered MRSA strains as per CLSI guidelines. A health care worker showing growth of MRSA from either the hand swab, 
nasal swab or both the sites was labelled MRSA carrier. After the identification of isolates and obtaining their methicillin resistance pattern, the percentage of MRSA carriage in the health care workers serving in different areas (Ward, ICU, Recovery and Emergency) of cardiac unit was calculated.

\section{Results and Discussion}

A total of 250 health care workers (127 from wards, 62 from ICUs, 37 from recovery and 24 from emergency) were screened by collecting swabs from hands and anterior nares. 88 staphylococcal isolates were obtained from samples of 250 health care workers screened. Out of 88 staphylococcal isolates, $42(48 \%)$ were identified as Staphylococcus aureus and 46 (52\%) were coagulase negative staphylococci (CONS). Out of 42 isolates of S. aureus, 21 (50\%) were MRSA. So, out of 250 health care workers, 21 were found to be MRSA carriers.

The percentage carriage of MRSA among health care workers serving in recovery, emergency, wards and ICUs was found to be $14 \%, 12 \%, 8 \%$ and $5 \%$ respectively (Table 1 ).

Table.1 Prevalence of MRSA in different areas

\begin{tabular}{|l|c|c|c|}
\hline S. No. & AREA & $\begin{array}{c}\text { NUMBER OF SUBJECTS } \\
\text { SCREENED }\end{array}$ & $\begin{array}{c}\text { NUMBER OF MRSA } \\
\text { CARRIERS }(\%)\end{array}$ \\
\hline $\mathbf{1 .}$ & Recovery & 37 & $5(14 \%)$ \\
\hline $\mathbf{2 .}$ & Emergency & 24 & $3(12 \%)$ \\
\hline $\mathbf{3 .}$ & Wards & 127 & $10(8 \%)$ \\
\hline $\mathbf{4 .}$ & ICUs & 62 & $3(5 \%)$ \\
\hline
\end{tabular}

In our study, highest carriage rate of MRSA was found among the subjects working in the recovery area $(14 \%)$. This could be attributed to the presence of multiple risk factors among the patients in this area like presence of cutaneous lesions, limited mobility, presence of urinary catheters and antibiotic intake. In a study conducted in Iran, highest nasal carriage of MRSA was found in surgical wards and the emergency department (Askarian et al., 2009).

In 1963, Stewart and Holt described the first major nosocomial epidemic of MRSA (Stewart et al., 1963). Numerous medical centers, first in Europe in the 1960s (Benner et al., 1968) and then in the United States in the 1970s, (Crossley et al., 1979) have reported outbreaks of nosocomial infections caused by MRSA. The first three methicillin-resistant isolates of $S$. aureus were among 5,440 S. aureus strains tested for methicillin resistance. All three were from the same hospital. These isolates were also resistant to antibiotics chemically unrelated to methicillin like streptomycin and tetracycline. The circumstances surrounding isolation of these three strains were noteworthy because they typify those associated with outbreaks of methicillin-resistant staphylococci even today. The first isolate was from a patient with eczema who had been treated with penicillin. Two subsequent isolates came from an infected finger of a nurse and from the wound of a post operative patient whom she had attended (Jevons et al., 1961). This occurrence of a multiple drug resistant strain in a carrier recently treated with a $\beta$ lactam antibiotic and subsequent nosocomial transmission literally through the hands of hospital personnel has become a familiar story (Barrett et al., 1968; Craven et al., 1981; Crossley et al., 1979). Therefore, screening of health care workers for MRSA carriage should be included in hospital infection control policy and necessary 
measures should be taken to prevent further transmission of such multidrug resistant pathogens.

\section{Acknowledgements}

The author is thankful to her father Sh. G.P. Dixit for his inseparable support and prayers, her mother Smt. V.P. Dixit for her boundless love and care, and her husband Dr.Aniket Shastri for his wholehearted support and encouragement. Also to the Head, Department of Microbiology, for providing the required research facilities.

\section{References}

Amorim, M.L., Vasconcelos, C., Oliveira, D.C., Azevedo, A., Calado, E., Faria, N.A. et al., 2009. Epidemiology of methicillin-resistant Staphylococcus aureus (MRSA) nasal colonization among patients and healthcare workers in a Portuguese hospital a pre-intervention study toward the control of MRSA. Microb Drug Resist. 15(1):19-26.

Anuprabha, S., Sen, M.R., Nath, G., Sharma, B.M., Gulati, A.K., Mohapatra, T.M. 2003. Prevalence of methicillin resistant Staphylococcus aureus in a tertiary referral hospital in eastern Uttar Pradesh. Indian $J$ Med Microbiol. 21:49-51.

Arora, S., Devi, P., Arora, U., Devi, B. 2010. Prevalence of methicillin-resistant Staphylococcus aureus (MRSA) in a tertiary care hospital in Northern India. J Lab Physicians. 2(2):78-81.

Askarian, M., Zeinalzadeh, A., Japoni, A., Alborzi, A., Memish, Z.A. 2009. Prevalence of nasal carriage of methicillin-resistant Staphylococcus aureus and its antibiotic susceptibility pattern in healthcare workers at Namazi Hospital, Shiraz, Iran. Int J
Infect Dis. 13:241-247.

Barrett, F.F., McGehee, R.F., Finland, M. $1968 . \quad$ Methicillin-resistant Staphylococcus aureus at Boston city hospital: bacteriologic and epidemiologic observations. $N$ Engl $J$ Med. 279:441-448.

Benner, E.J., Kayser, F.H. 1968. Growing clinical significance of methicillinresistant Staphylococcus aureus. Lancet 292:741-744.

Chaudhury, A., Kumar, A.G. 2007. In vitro activity of antimicrobial agents against oxacillin resistant staphylococci with special reference to Staphylococcus haemolyticus. Indian J Med Microbiol. 25(1):50-52.

Craven, D.E., Reed, C., Kollisch, N., DeMaria, A., Lichtenberg, D., Shen, K. et al., 1981. A large outbreak of infections caused by a strain of Staphylococcus aureus resistant to oxacillin and aminoglycosides. Am J Med. 71(1):53-58.

Crossley, K., Landesman, B., Zaske, D. 1979. An outbreak of infections caused by strains of Staphylococcus aureus resistant to methicillin and aminoglycosides. II. Epidemiologic studies. J Infect Dis. 139(3):280-287.

Edmond, M.B., Wallace, S.E., McClish, D.K., Pfaller, M.A., Jones, R.N., Wenzel, R.P. 1999. Nosocomial bloodstream infections in United States hospitals: A three year analysis. Clin Infect Dis. 29:239-244.

Farzana, K., Rashid, Z., Akhtar, N., Sattar, A., Khan, J.A., Nasir, B. 2008 Nasal carriage of staphylococci in health care workers: Antimicrobial susceptibility profile. Pak J Pharm Sci. 21(3):290-294.

Goyal, R., Das, S., Mathur, M. 2002. Colonisation of methicillin resistant Staphylococcus aureus among health care workers in a tertiary care hospital 
of Delhi. Indian J Med Sci. 56:321324.

Ibarra, M., Flatt, T., Van Maele, D., Ahmed, A., Fergie, J., Purcell, K. 2008. Prevalence of methicillin-resistant Staphylococcus aureus nasal carriage in healthcare workers. Pediatr Infect Dis J. 27(12):1109-1111.

Jevons, M.P. 1961. Celbenin-resistant staphylococci. BMJ. 1:124-125.

Kaminski, A., Kammler, J., Wick, M., Muhr, G., Kutscha-Lissberg, F. 2007. Transmission of methicillin-resistant Staphylococcus aureus among hospital staff in a German trauma centre: a problem without a current solution? $J$ Bone Joint Surg Br. 89(5):642-645.

Kesah, C., Redjeb, S.B., Odugbemi, T.O., Boye, C.S.B., Dosso, M., Achola, J.O.N. et al., 2003. Prevalence of methicillin-resistant Staphylococcus aureus in eight African hospitals and Malta. ClinMicrobiol Infect. 9:153156.

Klevens, R.M., Edwards, J.R., Richards, C.L., Horan, T.C., Gaynes, R.P., Pollock, D.A. et al., 2007. Estimating health care-associated infections and deaths in US hospitals. 2002. Public Health Rep. 122(2):160-166.

Mekviwattanawong, S., Srifuengfung, S., Chokepaibulkit, K., Lohsiriwat, D., Thamlikitkul, V. 2006. Epidemiology of Staphylococcus aureus infections and the prevalence of infection caused by community-acquired methicillinresistant Staphylococcus aureus in hospitalized patients at Siriraj hospital. J Med Assoc Thai. 89 Suppl 5:106117.

Mulla, S., Patel, M., Shah, L., Vaghela, G. 2007. Study of antibiotic sensitivity pattern of methicillin resistant Staphylococcus aureus. Ind J Crit Care Med. 11(2):99-101.

Nimmo, G.R., Pearson, J.C., Collignon, P.J.,
Christiansen, K.J., Coombs, G.W., Bell, J.M. et al., 2007.Prevalence of MRSA among Staphylococcus aureus isolated from hospital inpatients, 2005: report from the Australian Group for Antimicrobial Resistance. Commun Dis Intell.31(3):288-296.

Pulimood, T.B., Lalitha, M.K., Jesudason, M.V., Pandian, R., Selwyn, J., John, T.J. 1996. The spectrum of antimicrobial resistance among methicillin resistant Staphylococcus aureus (MRSA) in a tertiary care centre in India. Indian $\mathrm{J}$ Med Res. 103:212-215.

Rajaduraipandi, K., Mani, K.R., Panneerselvam, K., Mani, M., Bhaskar, M., Manikandan, P. 2006. Prevalence and antimicrobial susceptibility pattern of methicillin resistant Staphylococcus aureus: A multicentre study. Indian $J$ Med Microbiol. 24(1):34-38.

Sachdev, D., Amladi, S., Natraj, G., Baveja, S., Kharkar, V., Mahajan, S. et al., 2003. An outbreak of methicillinresistant Staphylococcal aureus (MRSA) infection in dermatology indoor patients. Indian $J$ Dermatol Venereol Leprol. 69:377-380.

Safdar, N., Narans, L., Gordon, B., Maki, D.G. 2003. Comparison of culture screening methods for detection of nasal carriage of methicillin-resistant Staphylococcus aureus: a prospective study comparing 32 methods. $J$ ClinMicrobiol. 41(7):3163-3166.

Shakya, B., Shrestha, S., Mitra, T. 2010. Nasal carriage rate of methicillin resistant Staphylococcus aureus at National Medical College Teaching Hospital, Birgunj, Nepal. Nepal Med CollJ. 12(1):26-29.

Stewart, G.T., Holt, R.J. 1963. Evolution of natural resistance to the newer penicillin. BMJ.1:308-311. 
Tahnkiwale, S.S., Roy, S., Jalgaonkar, S.V. 2002. Methicillin resistance among isolates of Staphylococcus aureus: Antibiotic sensitivity pattern and phage typing. Indian $J$ Med Sci. 56:330-334.

Tiemersma,

E.W.,

Bronzwaer, SLAM.,Lyytikäinen, O., Degener, J.E., Schrijnemakers, P., Bruinsma, N. et al., 2004. Methicillin-resistant Staphylococcus aureus in Europe, 1999-2002. Emerg Infect Dis. 10(9):1627-1634.

Verma, S., Joshi, S., Chitnis, V., Hemwani, N., Chitnis, D. 2000. Growing problem of methicillin resistant staphylococci- Indian scenario. Indian J Med Sci. 54:535-540.

Verwer, P.E., Robinson, J.O., Coombs, G.W., Wijesuriya, T., Murray, R.J., Verbrugh, H.A. et al., 2011.
Prevalence of nasal methicillinresistant Staphylococcus aureus colonization in healthcare workers in a Western Australian acute care hospital. Eur J ClinMicrobiol Infect Dis. Sep 10.

Vidhani, S., Mehndiratta, P.L., Mathur, M.D. 2001. Study of methicillin resistant S.aureus (MRSA) isolates from high risk patients. Indian J Med Microbiol. 19(2):13-16.

Vos, M.C., Behrendt, M.D., Melles, D.C., Mollema, F.P., de Groot, W., Parlevliet, G. et al., 2009. 5 years of experience implementing a methicillin-resistant Staphylococcus aureus search and destroy policy at the largest university medical center in the Netherlands. Infect Control HospEpidemiol. 30(10):977-984.

\section{How to cite this article:}

Rakhi Dixit. 2018. Comparison of Methicillin Resistant Staphylococcus aureus (MRSA) carriage among Health Care Workers Serving in Different Areas of Cardiac Unit of a Tertiary Care Hospital, India. Int.J.Curr.Microbiol.App.Sci. 7(07): 1348-1353. doi: https://doi.org/10.20546/ijcmas.2018.707.160 